\title{
Do santuário do deserto ao santuário do corpo de Jesus (Jo 2,13-22)
}

\author{
From the Shrine of the Desert to the Shrine of the \\ Body of Jesus (Jn 2: 13-22)
}

\section{Del santuario del desierto al santuario del cuerpo de Jesús (Jn 2: 13-22)}

\author{
Gilvan Leite de Araujo*
}

\begin{abstract}
RESUMO
O Templo de Jerusalém ocupa lugar de destaque na narrativa do Quarto Evangelho. Enquanto nos Sinóticos Jesus transita primordialmente na Sinagoga, no Evangelho de João ele transita particularmente em torno ao Templo. A narrativa da Purificação do Templo (Jo 2,13-22) coloca Jesus em situação não pouco amigável com os que exerciam comércio ou cambio nas portas do Templo. Contudo, a narrativa joanina evoca as tradições de Israel, em particular o Santuário do Deserto, o Santuário de Silo e, propriamente, o Templo de Jerusalém. Um estudo da evolução do Santuário do Deserto ao Templo de Jerusalém permite melhor compreensão da intenção do autor ao compor a sua narrativa. Palavras-chaves: Pentateuco; templo de Jerusalém; tenda do deserto; santuário de Silo; Quarto Evangelho.
\end{abstract}

\begin{abstract}
The Temple of Jerusalem occupies a prominent place in the narrative of the Fourth Gospel. While the Synoptics Jesus circulates mainly around the Synagogue, the Gospel of John, he travels particularly around the temple. The narrative of the Cleansing of the Temple (Jn 2,13-22) puts Jesus in a situation not just friendly with those engaged in commerce or exchange on the doors of the temple. However, the Johannine narrative evokes the traditions of Israel, particularly, the Shrine of the Desert, the Shrine of Silo and, specifically, the Temple of Jerusalem. A study of the evolution of the Sanctuary from the Desert to the Temple of Jerusalem allows a better understanding of the intent of the author to compose his narrative.

Keywords: Pentateuch; temple of Jerusalem; desert tent; Silo shrine; Fourth Gospel.

\section{RESUMEN}

El Templo de Jerusalén ocupa un lugar destacado en la narrativa del Cuarto Evangelio. Mientras que en los Sinópticos Jesús transita principalmente por la Sinagoga, en el Evangelio de Juan transita particularmente por el Templo. La narrativa de la Purificación del Templo (Jn 2,13-22) pone a Jesús en una situación no hostil para aquellos que comerciaban o cambiaban a las puertas del Templo. Sin embargo, la narrativa de Juan evoca las tradiciones de Israel, en particular el Santuario del Desierto, el Santuario de
\end{abstract}

* Doutor em Teologia Bíblica pelo Angelico de Roma e Pós-Doutorado em Teologia Bíblica pela Universidade Gregoriana de Roma. Professor Assistente Doutor do Programa de Estudos Pós-Graduados em Teologia da PUC-SP. 
Silo y, propiamente, el Templo de Jerusalén. Un estudio de la evolución del Santuario del desierto al Templo de Jerusalén permite una mejor comprensión de la intención del autor al componer su narrativa.

Palabras clave: Pentateuco; templo de Jerusalén; tienda del desierto; santuario Silo; Cuarto Evangelio.

\section{Tenda/Santuário}

O primeiro santuário de Israel foi a Tenda da Reunião ou do Encontro que, possivelmente, cotinha a Arca da Aliança (Ex 25,8ss). As narrativas de Êxodo 25-31 e 36-40 descrevem detalhadamente as diversas partem que compunham esta tenda, enquanto o Livro de Levítico descreve os ritos cultuais nele praticado (THOMPSON, 1997, p. 277).

A Tenda da Reunião ou do Encontro era o lugar onde Deus se encontrava com Moisés "face-a-face" (Ex 33,11) e lhe fala boca-a-boca (Nm 12,8). Acima de tudo, era o lugar onde Israel podia falar com Deus através de Moisés (Ex 29,42-43; 30,36; 33,7). Originalmente a expressão utilizada era "morada" (miskan), que indica residência temporária, própria da condição nômade (cf. Nm 24,5; Jz 8,11; 2Sm 7,6) (VAUX, 1998, p. 295). As narrativas sacerdotais adotaram esta expressão arcaica para expressar o modo da habitação de Deus na terra, que vive no céu, preparando, assim, a doutrina judaica da Shekinah que São João retomará com o tema da encarnação do Verbo (cf. Jo 1,14).

A presença divina na Tenda tende a se tornar estável na tradição sacerdotal, que se manifesta com a descida da "nuvem" que bloqueava a entrada da Tenda (cf. Ex 33,9) subindo após o término do diálogo (cf. Nm 12,4-10). Contudo, a narrativa do Êxodo deixa transparecer que a nuvem tenha tomado posse permanente da Tenda durante toda a caminhada do deserto (cf. Ex 40,34-38; Nm 9,15-23) (VAUX, 1998, p. 296).

Sabe-se que quando Israel chegou as portas da Terra Prometida, estabeleceu a Tenda nas estepes de Moab (cf. Nm 25,6) e, após o ingresso na Terra, ela foi estabelecida em Silo (cf. Js 18,1; 19,51; S1 78,60; $1 \mathrm{Sm}$ $1,7.9 ; 3,15)$. Segundo Vaux, a Tenda na qual Davi instalou a Arca não é tenda do período do deserto (cf. $2 \mathrm{Sm} 6,17 ; 1 \mathrm{Rs} 8,4$ ). O que leva o Cronista a tenta estabelecer vínculo (1Cr 16,39; 21,29; $2 \mathrm{Cr} 1,3-6)$, estabelecendo a tenda em Gabaon (VAUX, 1998, p. 297-298).

\section{Tenda da Reunião e objetos sagrados}

Assim como a Arca é concebida de modo diferente entre as diversas tradições, seja enquanto paládio de guerra ou mero escabelo, o mesmo acon- 
tece com o tema da Tenda da Reunião. A Tenda da Reunião é sem dúvida a mais forte instituição relacionada com a presença de Iahweh em todo AT.

O Santuário do Deserto teria sido construído ainda durante o período do deserto, ou seja, antes da posse da terra de Canaã, dentro daquilo que Haran chama de "utopia sacerdotal" (HARAN, 1978, p. 149). O autor defende que a Tenda do Deserto como descrita pela tradição sacerdotal é exagerada e nunca existiu em Israel (HARAN, 1978, p. 189).

O Santuário do Deserto foi erigido ainda durante a permanência dos israelitas no Monte Sinai, momento o qual Iahweh estabeleceu uma Aliança com os Israelitas, tendo suas "cláusulas" prescritas no Decálogo. Ela surge como abrigo para a Arca da Aliança que continha as duas Tábuas da Lei. A Tenda da Reunião acompanhou a peregrinação dos israelitas durante toda a sua marcha pelo deserto até a chegada a Terra Prometida. Chegando ao seu destino o Santuário permaneceu por um breve período de tempo em Guilgal (cf. Js 4,19;5,10) e logo, em seguida, foi transladada para Silo, lugar no qual, diante do Santuário, os israelitas fizeram a partilha da Terra Prometida (cf. Js $18,1-10 ; 19,51 ; 1 \mathrm{Sm} 2,18-23$ ). Segundo o relato sacerdotal, o Santuário do Deserto permaneceu em Silo até o seu translado para a Cidade de Davi e de lá para o Templo de Salomão. Não existe nenhuma alusão, no relato sacerdotal, de que o Santuário tenha saído de Silo para algum outro lugar até o seu translado por Davi. Contudo, Juízes 20,26-27 narra a presença da Arca da Aliança em Betel e em Gabaon (1Cr 16,39; 21,29 e $2 \mathrm{Cr}$ 1,3-6). Segundo Haran, o relato da Arca da Aliança em Betel e em Gabaon é somente uma tentativa forçada de um tardo historiógrafo para justificar os relatos do livro dos Reis (cf. 1Rs 3,4) (HARAN, 1978, p. 200). 1Reis 3,4 relata a Arca da Aliança em Gabaon, onde o próprio Salomão vai apresenta-se diante de Iahweh e oferecer sacrifícios, sendo que após a construção do Templo em Jerusalém é relatado que a Arca é transladada da Cidade de Davi, que é Sião. Aqui permanece uma dúvida se durante a construção do Templo a Arca tenha sido transladada de um lugar para outro, que é uma possibilidade não muito plausível. Contudo, Silo era o lugar por excelência com o qual o Santuário do Deserto é relacionado pela tradição sacerdotal, até a sua tomada pelos filisteus.

1Reis 8,4 relatada o translado da Arca da Aliança junto com a Tenda Santuário do Deserto. Contudo, em 1Samuel 1,7.24 o autor deixa transparecer que, em Silo, existiria um templo estável, mas tal hipótese é contestada com o relato de 2 Samuel 7,6-7, no qual Iahweh afirma habitar em uma tenda móvel que acompanhava a peregrinação errante dos israelitas (HARAN, 1978, p. 201). O relato sacerdotal da tenda em Silo assume a 
forma da tradição do Templo de Jerusalém, como um meio de exaltar a importância e a sacralidade da Tenda da Reunião como sendo um verdadeiro Templo dentro dos padrões do Antigo Oriente ou, possivelmente, trata-se de uma lenda transmitida oralmente e aceita pelo autor sacerdotal (HARAN, 1978, p. 203). Leve-se em consideração que durante a permanência da Arca em Silo, este assume o posto de "santuário central" de Israel por tal presença e assim permanecerá até a tomada da Arca pelos filisteus e posterior retorno para Cariat-Iarim (cf. 1Sm 7,1).

A correspondência entre a Tenda Sacerdotal e o Templo de Salomão é evidente, em primeiro lugar pelos objetos: querubins e a Arca no interior do "Santo", a mesa, a lâmpada e o altar do incenso e o altar do sacrifício. Em ambos os relatos, os objetos são feitos ou revestidos de ouro, amplo uso de madeira, de cobre e de bronze. O que chama a atenção é a estrutura altamente elaborada e pesada da Tenda do Deserto, tendo em vista que os israelitas vivem uma realidade nômade, que pressupõe elementos leves para o deslocamento de um lugar para o outro, bem como a ausência de alguns materiais difíceis de serem encontrados em ambiente desértico. Haran salienta que os exegetas são do parecer que o autor sacerdotal projetou, talvez no pós-exílio, uma imagem do Templo de Salomão na história do Êxodo (HARAN, 1978, p. 194) e que o relato seria uma história de ficção (HARAN, 1978, p. 197). Contudo, a conexão entre a Tenda da Reunião do relato sacerdotal e o Templo de Salomão não é apenas uma retro projeção da escola sacerdotal e/ou uma história de ficção, pois o relato nasce a partir de um substrato histórico transmitido oralmente por gerações. Este substrato pertence a uma antiga e autêntica tradição (HARAN, 1978, p. 195). A tradição, oralmente, transmitida fala de um Santuário do Deserto, que é na realidade uma tenda móvel, próprio para a vida nômade. Neste sentido, o santuário móvel não deveria ser tão majestoso e suntuoso como foi descrito posteriormente, mas o fato dele ser descrito em tal magnitude não quer dizer que não tenha existido e que se trate somente de uma ficção ou uma invenção de alguma mente criativa.

Pode-se também afirmar que o santuário não era apenas uma tenda provisória, tendo em vista que após a tomada de posse de Canaã ela permanece durante várias gerações (HARAN, 1978, p. 196) e, ao mesmo tempo, ela não se coloca em pé de igualdade com os templos construídos em Israel a não ser em relação ao Templo de Jerusalém, que será o seu legítimo sucessor.

A relação entre a Arca da Aliança e a Tenda da Reunião é uma questão de debate entre os exegetas. O relato de Êxodo 33,7-11 deixa transparecer 
que à Tenda da Reunião era um lugar de manifestação teofânica divina, aos moldes proféticos, sem a presença da Arca, ou seja, a tenda seria um lugar para receber oráculos e consultar a Iahweh. De fato, o relato não faz nenhuma menção a Arca da Aliança, enquanto o relato de Números 10,33-36 e 14,44 fala somente da Arca sem fazer nenhuma referência à tenda. Em todo caso, durante o período de Silo, as duas instituições são unificadas formando o santuário central por excelência de Israel (CLEMENTS, 1965, p. 36-39).

\section{Tradição de Silo}

Após a entrada na terra Prometida, a Arca junto com a Tenda e os Objetos Sagrados foram estabelecidos em Silo, que se tornará o santuário central de Israel (cf. Js 18,1) (SCHELEY, 1989, p. 94-97). Após a conquista da Terra Prometida a sua divisão entre as doze tribos de Israel se deu justamente em Silo, à entrada da Tenda da Reunião, na presença de Iahweh (Cf. Js 18,1-19,51).

A tradição de Silo está ligada diretamente com aquela do deserto no que corresponde à vida cultual dos israelitas. Silo, durante o período pré-monárquico abarca e reelabora as tradições nômades do deserto, como da Tenda (Js 18,1; 19,51b;22,19.29; 1Sm 2,22b; S1 78,60.67); da Arca da Aliança (1Sm 3,3; 4,4-6; 14,18); do sacerdócio de Aarão (Js 19,51 b; 21,1-2; 22,12-13.30-32; 24,33; 1Sm 1-4); do altar (Js 22,9-34) e do 'ephod (1Sm 14,3).

Os textos sagrados expressam um profundo silêncio sobre a vida cultual de Israel durante o período de Silo. Existem referências às tradições do deserto, mas não se sabe muito da prática cultual. Encontra-se somente referência a esta Festa anual dedicada a Iahweh. Não existe uma unanimidade entre os exegetas a respeito desta festa anual celebrada em honra de Iahweh. Roland de Vaux afirma que as descrições feitas em Juízes 21,19 e 1Samuel 1,3 correspondem de fato à Festa de Sucot em suas origens (VAUX, 1978, p. 531), enquanto Schley, seguindo Hengstenberg, (SCHELEY, 1989, p. 22) acredita tratar-se da Festa da Páscoa (SCHELEY, 1989, p. 194). Contudo, a maioria dos exegetas tendem a identificar a expressão Festa de Iahweh em Juízes 21,19 e 1Samuel 1,3 com a Festa de Sucot (VAUX, 1978, p. 22).

Silo, sem dúvida, foi o principal santuário de Israel durante o período pré-monárquico. O Santuário de Silo tendo servido como um central anfiteísmo santuário, caso tenha existido tal ideia de anfiteísmo em Israel 
ou não, foi proeminente por abrigar a Tenda e a Arca da Aliança. Uma das principais funções deste santuário foi de assegurar uma unidade tribal de Israel junto com outra importante instituição chamada de "anciãos de

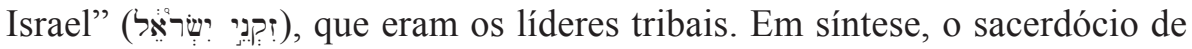
Silo e Anciãos de Israel foram capazes de, durante muito tempo, assegurar a unidade e a autonomia tribal e uma relativa segurança das doze tribos de Israel durante o período pré-monárquico (COHEN, 1965, p. 62-63), bem como pelo seu papel no nascimento da monarquia de Israel.

Será durante o período de Silo que a vida cultual de Israel terá um grande avanço, seja pelas tradições israelitas, seja pela então influência da já estabelecida vida cultual de Canaã. $\mathrm{O}$ intercâmbio cultural e religioso entre Canaã e Israel marcará profundamente a vida cultual israelita, porém, sem perder a sua essencialidade, ou seja, de Povo da Aliança.

\section{De Silo para Sião}

O translado do Tenda da Reunião e da Arca da Aliança encontra-se no Primeiro Livro dos Reis o qual descreve a ascensão de Davi e o declínio de Saul.

A Arca da Aliança após ser saqueada será devolvida pelos filisteus e ficará por vinte anos em Cariat-Iarim, na casa de Abinadab (cf. 1Sm 7,1-2). Somente quando Davi ascende ao trono e resolver estabelecer o território jebuzita como capital do reino é que decidirá transladar a Arca para a Cidade de Davi. A narrativa é construída a partir de fatos estranhos, como a procissão festivas e a morte de Oza que ao tocar na Arca para que esta não caísse da carroça foi imediatamente fulminado por Iahweh. O fato gera medo em Davi, resolvendo deixá-la na casa de Obed-Edom. Após a benção da casa deste, Davi resolve terminar o translado para a sua cidade (cf. 2Sm 6). Um fato particular é que quando a Arca da Aliança chega à cidade de Davi, ela será depositada "no seu lugar", numa Tenda que Davi havia preparado especialmente para abrigá-la (cf. 2Sm 6,17). Nesse sentido a narrativa deixa transparecer que já não exista mais a Tenda que anteriormente abrigava a Arca, obrigando a construir um lugar adequado para depositá-la até a construção do Templo.

O Salmo 132 narra o translado descrito em 2Samuel 6. O salmista descreve que a Arca se encontrava em lugares distintos (Éfrata; Campos de Jaar), configurando a ideia de peregrinação, mas prossegue o salmista afirmando que Iahweh escolheu a Sião como sua morada. Contudo, fala-se de Arca peregrina, mas não existe menção alguma ao aparato que a abriga- 
va, como uma tenda. Em todo caso, após a instalação da Arca na Cidade de Davi, posteriormente, após a ascensão de Salomão e a construção do Templo de Jerusalém, ela será "definitivamente" instalada (cf.1Rs 5-8).

Roland de Vaux salienta o Templo de Jerusalém como hereditário da Tenda do Deserto e do Santuário de Silo (VAUX, 1978, p. 309). Assim se estabelece, através da Arca da Aliança, estreito vínculo entre a Tenda do Deserto, o Santuário de Silo e o Templo de Jerusalém.

Uma particularidade do relato do translado da Arca por Davi é que não se faz menção da Tenda da Reunião e nem aos objetos sagrados e, por outro lado, Davi arma uma Tenda em Sião para abrigar a Arca da Aliança (cf. 2Sm 6,17). Outra particularidade é a menção a Arca sobre a qual é invocado o nome de Iahweh dos Exércitos, que se assenta sobre os querubins (2Sm 6,2). Indagando sobre a questão da Tenda se pode indagar: teria Davi edificado uma nova Tenda para abrigar a Arca ou apenas teria transferido a antiga Tenda para Sião? Caso Davi tenha edificado uma nova Tenda, o que teria acontecido com a Tenda de Silo ou não existia uma Tenda a Silo, ou teria a Tenda sido destruída pelos filisteus? A menção à tenda desaparece no relato de Crônicas (cf. 1Cr 15,3), mas por outro lado, Iahweh afirma que passava de tenda em tenda (cf. $1 \mathrm{Cr}$ 17,5), contrário à afirmação de 2Sm 7 na qual Iahweh afirma que passou errante pelos acampamentos dos israelitas "debaixo de uma tenda e um abrigo" $(2 \mathrm{Sm} \mathrm{7,6).}$

A perspectiva histórica ilustra, como um caleidoscópio, a imagem da Tenda do Encontro e/ou o Santuário do Deserto até a sua forma estável final, configurada pelo Templo de Jerusalém. Além disso, leva-se em conta que enquanto a teologia do sul irá subsistir a partir das ideias de trono eterno de Davi e o Templo de Iahweh, a teologia do norte se constrói a partir da tradição patriarcal e mosaica. Assim, possivelmente, à época do Novo Testamento, a relação entre Santuário/Tenda e Templo esteja vinculado as tradições do norte e do sul.

Partindo desse pressuposto, a relação estabelecida entre Santuário e Templo, proposto pelo Quarto Evangelho este possua tal significado. Leva-se em conta que no diálogo entre Jesus e a Samaritana, tal perspectiva reaparece, quando esta questiona Jesus sobre o lugar de culto [Garizim ou Jerusalém?] (cf. Jo 4,20).

\section{Templo de Jerusalém}

Davi, tendo transladado a Arca da Aliança para a sua nova capital, a configurou como capital política e religiosa. A narrativa de 2 Samuel 7 
descreve Davi e Natã, no qual o primeiro expõe o desejo de construir uma morada fixa, tendo em vista que ele já habita numa casa de cedros. $\mathrm{Na}$ sequência, entra o próprio Senhor dissuadindo do projeto, pois este será tarefa do seu sucessor. A narrativa prossegue com Iahweh afirmando que não será Davi a construir uma casa, mas Ele próprio construirá uma casa/ dinastia para Davi. Outra narrativa, no entanto, afirma que o impedimento para Davi construir a casa para Iahweh é o fato de ter as mãos manchadas de sangue (cf. $1 \mathrm{Cr} 22,8-10$ ).

Uma particularidade do relato do translado da Arca por Davi é que não se faz menção da Tenda da Reunião e nem aos objetos sagrados e, por outro lado, Davi arma uma Tenda em Sião para abrigar a Arca da Aliança (cf. $2 \mathrm{Sm} \mathrm{6,17).} \mathrm{Outra} \mathrm{particularidade} \mathrm{é} \mathrm{a} \mathrm{menção} \mathrm{a} \mathrm{Arca} \mathrm{sobre} \mathrm{a} \mathrm{qual} \mathrm{é}$ invocado o nome de Iahweh dos Exércitos, que se assenta sobre os querubins (2Sm 6,2). Indagando sobre a questão da Tenda podemos perguntar: teria Davi edificado uma nova Tenda para abrigar a Arca ou apenas teria transferido a antiga Tenda para Sião? Caso Davi tenha edificado uma nova Tenda, o que teria acontecido com a Tenda de Silo ou não existia uma Tenda a Silo, ou teria a Tenda sido destruída pelos filisteus? A menção à tenda desaparece no relato de Crônicas (cf. 1Cr 15,3), mas por outro lado, Iahweh afirma que passava de tenda em tenda (cf. 1Cr 17,5), contrário à afirmação de $2 \mathrm{Sm} 7$ na qual Iahweh afirma que passou errante pelos acampamentos dos israelitas "debaixo de uma tenda e um abrigo" (2Sm 7,6). Outra questão é o relato sobre os querubins que possuem a função de trono. A menção ao nome de Iahweh dos Exércitos entra dentro do que chamaremos de teologia do "Nome de Iahweh".

Após a sua permanência na Cidade de Davi, a Arca será novamente translada para o Templo de Jerusalém segundo a narração de $1 \mathrm{Rs} 8$ e $2 \mathrm{Cr}$ 5. O relato do translado da Arca da Cidade de Davi para Jerusalém segue o modelo do translado feito por Davi de Silo para a Cidade de Davi.

A Arca permanece no Templo de Jerusalém até o período anterior ao Exílio da Babilônia; depois disto, desconhece-se o seu paradeiro e como ela tenha desaparecido. O AT guarda um certo silêncio a este respeito. A primeira hipótese é de que durante o reinado de Roboão, a Arca tenha sido levada junto com os despojos de guerra para o Egito, durante a invasão de Sesac (1Rs 14,25-28). Uma segunda hipótese é que, após a vitória do rei de Israel Joás sobre o rei de Judá Amasias, a Arca da Aliança tenha sido levada, também, como despojo de guerra para o reino do norte (cf. 2Rs 14,8-14). A terceira hipótese aponta sobre a apostasia de Manassés, que profanou o Templo com altares, imagens e cultos pagãos (cf. 2Rs 21,4-6). 
A quarta e última hipótese aponta para o exílio da Babilônia, na qual a Arca tenha sido ou conduzida para a Babilônia ou tenha sido destruída. Contudo, pelo fato de a Arca da Aliança não constar na lista dos objetos saqueados do Templo leva a pensar que ela, provavelmente, tenha sido eliminada durante o reinado de Manassés, reforçando a terceira hipótese (cf. 2Rs 25,13-17; Jr 52,17-23). Uma incógnita sobre o paradeiro da Arca nos é apresentada em 2Mc 2,7-8, onde Jeremias a teria escondido em uma caverna, mas o relato não goza de muita credibilidade, podendo apenas ser um modo de legitimar a continuidade do culto apesar da ausência dos objetos sagrados, que compunham o Templo.

A Tenda Santuário do Deserto e, posteriormente, o Templo de Jerusalém aparecem como moradia de Iahweh. A Tenda do Deserto surge por vontade própria de Iahweh: "Faze-me um santuário, para que eu possa habitar no meio deles. Farás tudo conforme o modelo da Habitação e o modelo da sua mobília que eu irei mostrar" (Ex 25,8-9), ao passo que o Templo de Jerusalém surge por vontade de Davi e iniciativa e Salomão: “...meu Pai Davi teve a intenção de construir uma casa para o Nome de Iahweh... Mas Iahweh disse... não serás tu quem edificará esta casa, e sim, teu filho..." (1Rs 8,17-19). Tais moradias após respectivas edificações vêm empossadas pelo seu dono, ou seja, Iahweh e a tomada de posse se faz através da manifestação da Nuvem que preenche a Tenda (Ex 40,34-35) e o Templo (1Rs 8, 10-13). A Presença Divina de Iahweh recebe o nome de Shekinah.

\section{Templo de Jerusalém em Jo 2,13-22}

A narrativa da Purificação do Templo está inserida na grande narrativa denominada "de Caná a Caná" que abrange Jo 2,1 a 4,54 (KIERSPEL, 2008, p. ${ }^{526-554)}$. No conjunto de Jo 2-4 Jesus transita entre Galileia e Judeia, particularmente sublinhando a subida de Jesus para Jerusalém por ocasião da Páscoa.

Os quatro evangelhos descrevem Jesus no Templo de Jerusalém realizando um ato atípico, ou seja, a expulsão dos vendilhões (cf. Mt 21,10-17; Mc 11,15-19; Lc 19,45-48; Jo 2,13-22). Contudo, a narrativa joanina se distingue das demais quanto a posição que ocupa no conjunto da obra, ou seja, enquanto os Sinóticos apresentam a ação de Jesus no Templo após a sua entrada em Jerusalém, praticamente no final da sua missão e pouco antes da sua paixão, o Quarto Evangelho aloca a narrativa no início da atividade pública de Jesus.

Situando a narrativa da purificação ao início do Evangelho, o autor o vincula com o tema da Páscoa Judaica, ou seja, no momento que Jesus sobe 
para Jerusalém a fim de se preparar para a celebração pascal, o que implica no processo de purificação ritual, tornando a pessoa apta para celebrá-la.

A participação da Páscoa Judaica implica no estado de pureza ritual. O livro de Números prescreve que o estado de impureza como impedimento para se celebrar a Páscoa. Tal situação de impureza deriva por causa de um morto e implica na proibição de celebrar a Páscoa do primeiro mês. A pessoa impedida de celebrar a Páscoa do primeiro mês por causa de um morto ou por estar em trânsito (viagem) fica obrigado celebrar a Páscoa do segundo mês (cf. Nm 9,6-14; Mpeshahim IX) (ARAUJO, 2017, p. 8485) Digno de nota sobre a questão da purificação ritual para a celebração da Páscoa Judaica é a narrativa de 2 Crônicas, que narra a celebração da Páscoa durante o reinado de Ezequias (716-687 a.C.) segundo convocação enviada pelo Rei a toda Israel (cf. 2 Cr 30,1). Nesta narrativa a celebração da Páscoa acontece durante o processo de purificação ritual de Israel e, devido ao processo de purificação, a celebração ocorre somente no segundo mês e (cf. 2Cr 30,2-3), mesmo assim, muitos não se encontram ainda em estado de pureza (cf. $2 \mathrm{Cr} 30,18-20)$. O subir para Jerusalém para a celebração é descrito como gesto de humildade e reconhecimento do senhorio de Deus (cf. 2Cr 30,1.6-14) (ARAUJO, 2017, p. 87-88)

O tema da purificação está vinculado como preparativo para a Festa das Tendas, mas não da Páscoa (cf. Lv 16). A Festa da Páscoa não prescrevia diretamente ritos de purificação, como a celebração de Yom Kipur que antecedia a Festa das Tendas. Nesse sentido, no que consistia o estado de pureza ritual para a celebração da Páscoa? Como visto acima são considerados impuros para a celebração da Páscoa pessoas que participam de um velório ou que está em trânsito (cf. Nm 9,6-14; Mpeshahim IX). Levando em consideração que estar próximo de uma pessoa morta torna alguém impuro, qual seria a prescrição para purificação? O livro de Levítico não menciona um estado de impureza por contato com uma pessoa morta. Tal afirmação aparece no livro de Números ao afirmar que o toca um cadáver torna a pessoa ritualmente impura por sete dias (cf. Nm 19,11). Nesse caso a pessoa impura deverá se purificar ao terceiro e ao sétimo dia com "água" (cf. Nm 9,12). O modo de purificação não é prescrito, possivelmente se trate de banho ritual. Números acrescenta que o local e os objetos próximo da pessoa que faleceu também está impuro por sete dias (cf. Nm 9,13-16). Fora tal prescrição não existe outra menção sobre estado de impureza ou ato de purificação para aquele que deseja participar da celebração da Páscoa.

Não sendo a impureza ritual o motivo da ação de Jesus ao "purificar" o Templo de Jerusalém. O que estaria em jogo para a sua atitude? 


\section{Preparativos para a celebração da Páscoa}

Não existe nenhuma prescrição no que diz respeito aos preparativos para a celebração da Páscoa. No período pós-exílico até a queda do Templo em 135 d.C. existe a prescrição da subida para Jerusalém para a celebração da Páscoa entre 14 e 15 de Nissan e no dia seguinte retorno para casa na qual se dava continuidade à celebração com a celebração dos Ázimos que durava sete dias. Fora a prescrição da Mishná sobre a eliminação de todo e qualquer fermento da casa antes do início das celebrações [Páscoa e Ázimos] (Mpeshahim 1-3), apenas existe a referência ao sacrifício do cordeiro pascal na véspera (14 de Nissan). O Quarto Evangelho faz menção a uma tradição popular de dar esmola para os pobres, para que eles tivessem condições necessária para celebrar a Páscoa (cf. Jo 13,29). Além disso, se comprava o necessário para a celebração (cf. Jo 13,29).

A única base antigo testamentária para legitimar um processo de purificação ritual encontra-se na narrativa do segundo livro das Crônicas.

O reinado de Ezequias (716-687 a.C.) marca um período de purificação religiosa em Judá após o reinado do seu pai Acaz (cf. 2Rs 18-20). O relato da Páscoa durante o reinado de Ezequias está relacionada com o tema da purificação, principalmente do Templo de Jerusalém. Curioso é que a Páscoa é celebrada no segundo mês, pois os sacerdotes não estavam santificados em número suficiente e o povo ainda não se tinham reunido em Jerusalém para celebrá-la no tempo indicado (cf. 2Cr 30,2-3), ou seja, no décimo quarto dia do primeiro mês. Esta celebração evoca o relato do livro de Números que prescreve a Páscoa do segundo mês por motivo de impureza ou viagem (ARAUJO, 2017, p. 87).

O subir para Jerusalém para a celebração da Páscoa é descrito como um gesto de humildade e de reconhecimento do senhorio de Deus, aceito por alguns e rejeitado por outros (cf. 2Cr 30,1.6-14). Deve-se nota que a Carta de Ezequias enviada às tribos de Judá e Israel prescreve a celebração da Festa do Ázimos, ou seja, do pão sem fermento (cf. 2Cr 30,13).

A narrativa de 2 Crônicas evidencia que a celebração ocorreu num clima de confusão, pois muitos dos participantes não estavam puros, conforme a prescrição da Lei, mesmo celebrando no segundo mês, o que leva o rei Ezequias a implorar a misericórdia divina em favor dos que se encontravam impuro, tendo as preces atendidas por Deus (cf. $2 \mathrm{Cr} 30,18$ 20). Em relação à celebração, o autor de Crônicas divide a celebração em duas partes, ou seja, a celebração da Páscoa (cf. 2Cr 30,15-20) e a celebração do Ázimos (cf. 2Cr 30,21-27). Na primeira parte os sacerdotes 
e os levitas ficam sobrecarregados com os sacrifícios que devem realizar. $\mathrm{Na}$ segunda parte, o autor informa que se celebrou durante sete dias a festa dos Ázimos junto com sacrifícios diários de comunhão. O clima de júbilo invade Jerusalém levando os sacerdotes, o rei e todo o povo a continuar celebrando por mais sete dias. Deste modo a celebração da Páscoa e dos Ázimos em 2Crônicas tem uma duração de quatorze dias. Todo o relato de Crônicas deixar transparecer que a celebração da Páscoa tem como finalidade a purificação cultual de Judá e Israel (ARAUJO, 2017, p. 87-88).

A relação entre Páscoa e Purificação, seguindo a narrativa joanina, poderia estar sob a influência da narrativa cronista? Caso positivo, qual seria a intenção do autor do Quarto Evangelho em estabelecer tal conexão?

O rei Ezequias sobe ao trono após o desastroso reinado Acaz, seu pai. Segundo a narrativa do segundo livro das Crônicas, Acaz não só destruiu os utensílios do Templo como o profanou (cf. 2Cr 28,24-25). Além disso, deposita a sua confiança no rei da Assíria.

\section{Análise Sinótica da Narrativa da Purificação do Templo nos Quatro Evangelhos}

A narrativa da "purificação do Templo" aparece nos quatro Evangelhos simultaneamente. Contudo, enquanto os Sinóticos alocam a narrativa após a entrada triunfal de Jesus em Jerusalém (Mt 21,12-17; Mc 11,11-19; Lc 19,45-48), o Quarto Evangelho a descreve ao início da sua missão, na primeira viagem (Jo 2,13-22). Outras particularidades distinguem, ainda, a narrativa Sinótica da narrativa Joanina:

As narrativas Sinóticas descrevem a narrativa da purificação do Templo de Jerusalém após a entrada triunfal de Jesus em Jerusalém e ao final da sua missão. Os três Evangelhos narram que imediatamente após a entrada em Jerusalém, Jesus vai ao Templo. Contudo, Mateus e Lucas divergem de Marcos sobre a questão temporal da narrativa. Nas narrativas de Mateus e Lucas a ação ocorre imediatamente ao entrar no Templo e depois se retira para Betânia (Mateus), enquanto Marcos afirma que Jesus entra no Templo, observa, se retira para Betânia e, no dia seguinte, retorna e realiza a sua ação.

Os três Evangelhos são concordes em afirmar que Jesus chama o Templo de "casa de oração" contrário ao uso que estava sendo dado, ou seja, "casa de ladrões", ou seja, lugar de comércio exploratório: 


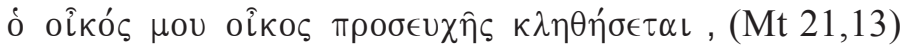

a casa minha casa de oração será chamada

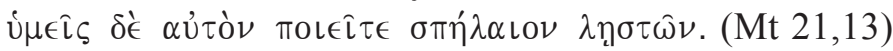

mas, dela fazeis covil de ladrões (bandidos)

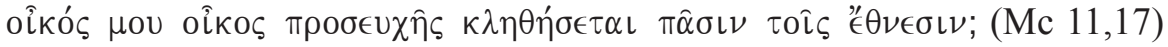

casa minha casa de oração será chamada para todas as nações

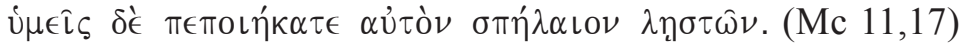

mas, tendes feito dela covil de ladrões

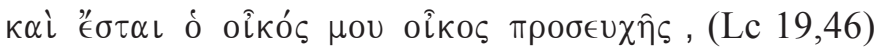

e será casa minha casa de oração

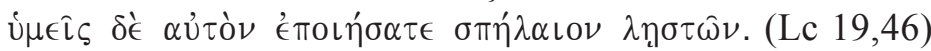

mas, fizestes da mesma um covil de ladrões

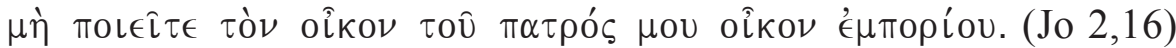
não façais da casa do meu Pai casa de comércio.

A importância da narrativa da purificação do Templo pode ser medida pelo que reflete nas comunidades cristãs. Contudo, a narrativa joanina difere significativamente das narrativas sinóticas em diversos aspectos. Segundo Zumstein, a narrativa joanina se distingue das narrativas sinóticas nos seguintes aspectos: a) somente o Quarto Evangelho faz menção ao gado graúdo (bois e ovelhas); b) o chicote feito por Jesus, derruba as moedas dos cambistas e fala aos vendedores de pombas; c) os Sinóticos se inspiram em Is 56,7, enquanto a narrativa joanina se inspira no Sl 69,10 (ZUMSTEIN, 2017, p. 136). Além disso, prossegue Zumstein, nos Sinóticos a purificação ocorre no fim da missão de Jesus, portanto, imediatamente antes da Paixão, enquanto em João exatamente ao início da sua missão (ZUMSTEIN, 2017, p. 136). Nesse sentido, enquanto nos Sinóticos a ação de Jesus na sua condenação à morte, no Quarto Evangelho a decisão de condenar Jesus ocorre após a ressurreição de Lázaro (Jo 11), enquanto a sua ação de purificação, a primeira em Jerusalém, resulta na indagação sobre sinal que o leva a tal atitude (cf. Jo 2,18). Léon-Dufour (2001, p. 197) sugere, com restrição, que a narrativa joanina esteja alocada ao início da vida pública de Jesus por questão teológica e, no caso, sugere o vínculo com a profecia de Malaquias. ${ }^{1}$

\footnotetext{
"Eis que vou enviar o meu mensageiro para que prepare um caminho diante de mim. Então, de repente, entrará em seu Templo o Senhor que vós procurais; o Anjo da Aliança, que vós desejais, eis que ele vem, disse Iahweh dos Exércitos. Quem poderá suportar o dia da sua chegada? Quem poderá ficar de pé, quando ele aparecer? Porque ele é como o fogo do fundidor e como a lixívia dos lavadeiros. Ele virá para fundir e purificar a prata. Ele purificará os filhos de Levi e os acrisolará como ouro e prata, e eles se tornarão para Iahweh aqueles que apresentam uma oferenda conforme a justiça” (Ml 3,1-3).
} 
Caso seja a profecia de Malaquias a base inspiradora para que a narrativa esteja ao início da vida pública de Jesus, esta estaria bem situada, pois o primeiro capítulo apresenta a figura de João Batista como aquele que viera endireitar o caminho do Senhor, como um sacerdote que testemunha o "cordeiro de Deus" (cf. Jo 1,16-34). Malaquias inicia a sua narrativa justamente mencionando o envio do mensageiro que prepara o caminho do Senhor (cf. Ml 3,1). Portanto, distinto da narrativa Sinótica, a narrativa joanina está sob a inspiração do Salmo 69,10 e de Malaquias 3,1-3. Nesse sentido, o corte primordial da narrativa é a apresentação da chegada do Messias.

Partindo desta prospectiva resta compreender a relação entre a chegada do Messias e o Templo de Jerusalém.

$\mathrm{Na}$ narrativa joanina o Templo assume uma chave de leitura, mas o autor aplica à ele três diferentes designações: templo (i€póv: vv. 14-15), ao santuário ( $\nu \alpha o ́ \varsigma: ~ v v . ~ 16-17)$ e casa (oîkos: vv. 19-20) e conclui a narrativa afirmando que o templo é o seu corpo (v. 21) (MOLONEY, 1990, p. 440). Para Moloney, o uso de "casa" em relação ao Templo tem como base a profecia de Isaías (Is 56,7), no qual o Templo é chamado diretamente, por Deus, de "minha casa" e "casa de oração" (MOLONEY, 1990, p. 441).

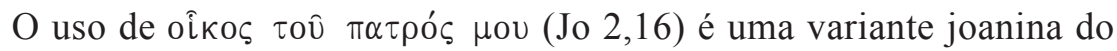
uso da LXX (SCHRENK, 1968, p. 777). Schrenk evoca Dalman, segundo o qual a distinção entre i $€$ óv, como designação do complexo do Templo, e $\nu \alpha o ́ \varsigma$, que se refere ao edifício do Templo, não encontra fundamento nos textos do NT (SCHRENK, 1968, p. 778). Para Schrenk, a expressão iєৎóv refere-se a todo o complexo do Templo (cf. Mt 12,6; At 24,6; 25,8; 1Cor 9,13), mesmo a lugares do Templo difícil de precisar (cf. Lc 22,53; Jo 5,14), assim como ao monte do Templo (cf. Mc 13,3). Além disso,

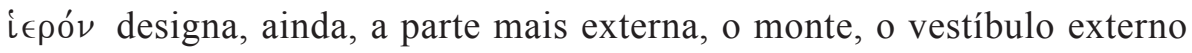
(SCHRENK, 1968, p. 778).

Curiosamente, Léon-Dufour relaciona Templo e Santuário de um modo particular, ou seja, segundo ele, o Santuário seria o interior do Templo (LÉON-DUFOUR, 2001, p. 199). Contudo, tal concepção foge do estilo literário do autor do Quarto Evangelho que trabalha com paralelos sinonímicos para construir a sua teologia. Assim, o uso de Templo e de Santuário possui função teológica que não pode simplesmente ser ignorada.

Simoens faz uma sugestão intrigante e curiosa sobre a relação dos dois substantivos próprios que se encontram relacionados no início da narrativa, ou seja, Jesus (= Deus Salva) e Jerusalém (Cidade da Paz). Segundo o autor, os prefixos dos dois substantivos, no grego, formam o 
substantivo grego i'ero-, o que pode sugerir o lugar do Templo (SIMOENS, 2016, p. 94-95).

A relação entre Tenda/Santuário ( $\nu \alpha o ́ \varsigma)$ e Templo (i€€óv) não pode ser entendida em termos de parte do Templo de Jerusalém, mas, partindo do estilo próprio do Quarto Evangelho, como evocando tradições distintas. Aqui, no caso, a tradição de Judá e a tradição do norte. De fato, a teologia do sul se baseava nos conceitos de eleição eterna de Davi e Templo de Jerusalém, enquanto, a teologia do norte se baseava nos conceitos de Patriarcas e Tradição Mosaica. Tal expediente literário é visível, por exemplo, no diálogo entre Jesus e Tomé, no qual este afirma ser Jesus Iahweh e Elohim, evocando imediatamente as tradições do sul e do norte (cf. Jo 20,28). Diante disso, quando o autor do Quarto Evangelho evoca as expressões i $€$ €óv e $v \propto o ́ \varsigma$ ele deseja evocar as tradições de Israel ligas à Tenda do Deserto, ao Santuário de Silo, ao Santuário da Cidade de Davi e, finalmente, ao Templo de Jerusalém.

Conclui-se que todo esse movimento possui uma função no Quarto Evangelho, pois progressivamente Tenda/Santuário e Templo são elevados ao seu ápice quando o novo Templo será o Pai e o Filho: "Ele, porém, falava do templo do seu corpo" (Jo 2,21); "Não vi nenhum templo nela, pois o seu templo é o Senhor, o Deus todo-poderoso, e o Cordeiro" (Ap $21,22)$. E o sentido próprio desse movimento encontra-se na narrativa da "Mulher Samaritana", na qual ela indaga sobre o verdadeiro santuário no qual sede adorar à Deus, Garizim ou Jerusalém, seguida da resposta de Jesus, que não será nem em um e nem no outro, mas em Espírito e Verdade (cf. Jo 20,24).

\section{Referências bibliográficas}

ARAUjO, G.L. Páscoa ou Páscoas Judaicas? Revista de Cultura Teológica, n. 89, p. 84-85, 2017.

CLEMENTS, R.E. God and temple: the presence of God in Israel's worship. Malden, MA: Blackwell, 1965.

COHEN, M.A. The Role of the Shilonite Priesthood. HUCA 36, p. 59-98, 1965.

HARAN, M. Temples and temple-service in ancient Israel: an inquiry into the character of cult phenomena and the historical setting of the Priestly School. Oxford: Clarendon Press, 1978.

KIERSPEL, L. "Dematerializing” religion: reading John 2-4 as a chiasm. Biblica 89, p. 526-554, 2008.

LÉON-DUFOUR, X. Lectura del Evangelio de Juan. Jn 1-4. Salamanca: Sígueme, 2001. 
MOLONEY, F.J. Reading John 2:13-22: the purification of the Temple. Revue Biblique, v. 97, n. 3, p. 432-452, 1990.

SCHRENK, G. to "i'ero,n”. In: KITTEL, G.; FRIEDRICH, G. GLNT. V. IV. Brescia: Paideia Editrice, 1968.

SCHLEY, D.G. Shiloh, a biblical city in tradition and history. JSOT - Supplement 63, Sheffield, 1989.

SIMOENS, Y. Évangile selon Jean. Paris: Éditions Jésuites de Paris, 2016.

THOMPSON, J.A. Santuario. In: BURKHARDT, H. et alii (Eds.). Grande Enciclopedia Illustrata della Bibbia. V. 3 (P-Z). Torino: Piemme, 1997.

VAUX, Roland de. Le istituzioni dell'Antico Testamento. Genova: Marietti, 1998.

VICENT, R. La festa ebraica delle Capanne (Sukkot). Interpretazioni midrashiche nella Bibblia e nel giudaismo antigo. Città del Vaticano: Libreria Editrice Vaticana, 2000.

ZUMSTEIN, J. Il Vangelo secono Giovanni. V. 1: 1,1-12,50. Torino: Claudiana, 2017.

Submetido em: 2-9-2019

Aceito em: 31-10-2019 